\title{
Familial non-cystic fibrosis mucus inspissation of respiratory tract
}

\author{
M. PERLMAN, J. WILLIAMS, M. HIRSCH, and J. BAR-ZIV* \\ From the Neonatal Unit and Department of Radiology, Soroka Medical Centre, Beer Sheva, Israel
}

\begin{abstract}
Perlman, M., Williams, J., Hirsch, M., and Bar-Ziv, J. (1975). Archives of Disease in Childhood, 50, 727. Familial non-cystic fibrosis mucus inspissation of respiratory tract. Two sibs, whose parents are first cousins, have had chronic obstructive airways disease from birth with recurrent otitis media, sinusitis, and mastoiditis. The disease, associated with clinically abnormal mucus, differs from other familial obstructive airways diseases and probably constitutes a new entity.
\end{abstract}

Familial chronic obstructive airways disease occurs in a number of entities which appear to be associated with abnormal respiratory tract mucus. We describe here a new form of familial obstructive respiratory tract disease in 2 sibs in which clinically abnormal mucus was a prominent feature.

\section{Case reports}

Case 1. A male infant was born to a healthy 28year-old gravida 4, para 3 woman after an uncomplicated pregnancy and normal term delivery. Birthweight was $3100 \mathrm{~g}$ and Apgar score at 1 minute was 9. Respiratory distress was noted on arrival in the nursery 2 hours postnatally. Examination showed central cyanosis, respiratory rate $80 / \mathrm{min}$, severe inspiratory retractions, and expiratory grunting. Breath sounds were nearly inaudible and there were medium râles at end-expiration over both lungs. Large amounts of an unusual viscid brown secretion were aspirated from the upper airways. Heart sounds and peripheral pulses were normal and, apart from lethargy, there were no other abnormal clinical findings.

Chest $x$-ray showed hyperinflation of both lungs consistent with air trapping (Fig. 1). The arterialized capillary blood $p \mathrm{H}$ was $7 \cdot 25$ and blood glucose was $35 \mathrm{mg} / 100 \mathrm{ml}$. The leucocyte count was $15400 / \mathrm{mm}^{3}$, with $73 \%$ neutrophils and a shift to the left. With frequent aspiration of the upper airways, added oxygen, intravenous sodium bicarbonate, and antibiotics, there was gradual improvement over 3 days. On day 3 dyspnoea and marked cyanosis recurred. The percussion note was hyper-resonant and breath sounds were inaudible over the left hemithorax. Chest $x$-ray showed left upper lobe collapse and air trapping in the rest of the lungs (Fig. 2). A catheter was passed into the left

Received 4 February 1975.

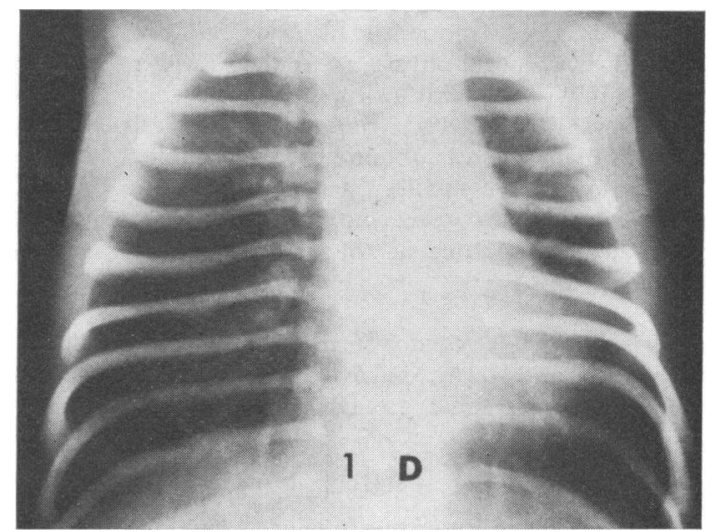

FIG. 1.-Case 1. Note marked hyperinflation of the lungs consistent with air trapping.

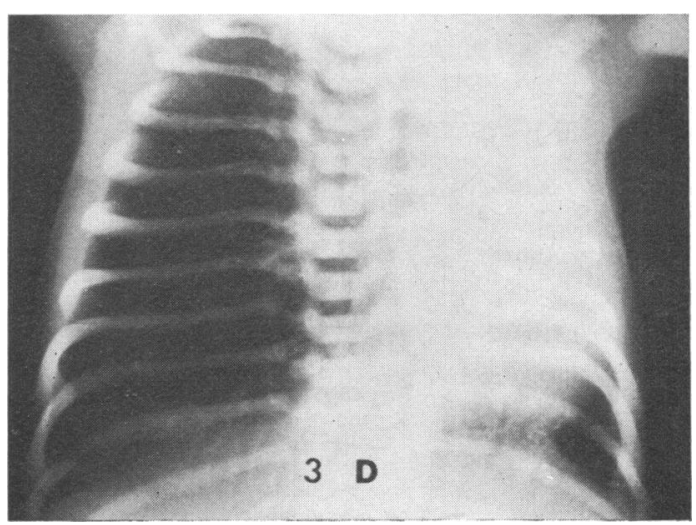

Fig. 2.-Case 1. Left upper lobe collapse and air trapping in the rest of the lungs. 
lower lobe bronchus using direct laryngoscopy and fluoroscopy, and bronchial lavage resulted in the aspiration of a small quantity of viscid brown secretion. Subsequently there was an increased accumulation of this secretion in the pharynx and chest $x$-ray on day 6 showed marked improvement.

On day 8 the clinical condition again deteriorated and chest $x$-ray showed a moderate degree of overinflation of the lungs without lobar collapse. Hourly bronchial toilet through an indwelling endotracheal tube was performed. The subsequent course was characterized by persistent tachypnoea and retractions of varying severity, cough, and wheezing. Repeat chest $x$-ray on day 13 showed hyperaerated lungs on both sides. Weight gain was normal and he was discharged at the age of 2 months. Repeated leucocyte counts were normal.

At home he was treated with chest physiotherapy and prophylactic ampicillin. Tachypnoea, retractions, cough, and episodes of wheezing and emphysema have become less marked during the first year and a half of life. The presence of stringy tenacious mucus in the mouth has been frequently observed. Chest $x$-ray at $2 \frac{1}{2}$ months showed only a mild degree of pulmonary overaeration. Bilateral otitis media at the age of 4 months was treated by tympanic paracentesis. Tenacious clear mucus was obtained with difficulty.

Laboratory investigations are summarized in Table I. Sweat electrolytes were normal. Two attempts to obtain duodenal juice at the age of 18 months were unsuccessful.

Case 2. A girl aged 8 years is the sister of Case 1 . Pregnancy and term delivery were normal and the birthweight was $3350 \mathrm{~g}$. On arrival in the nursery,

TABLE I

Laboratory investigations of Cases 1 and 2

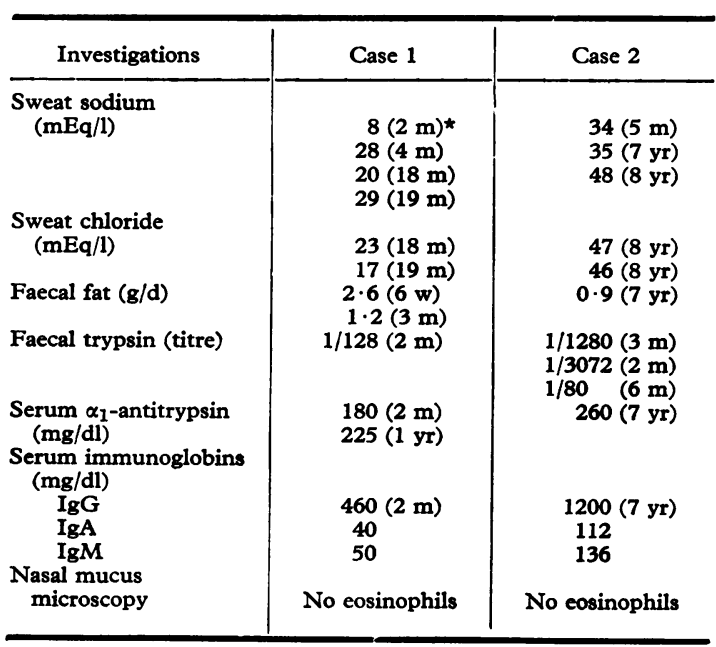

$\star$ Age of patient at time of examination is given in parentheses. central cyanosis, dyspnoea, expiratory grunting, and basal râles were recorded. Chest $x$-ray showed a mild degree of pumonary hyperinflation and partial collapse of the left upper lobe (Fig. 3a, b). The next day her condition worsened and chest $x$-ray now showed progression to complete collapse (Fig. 4). By day 4

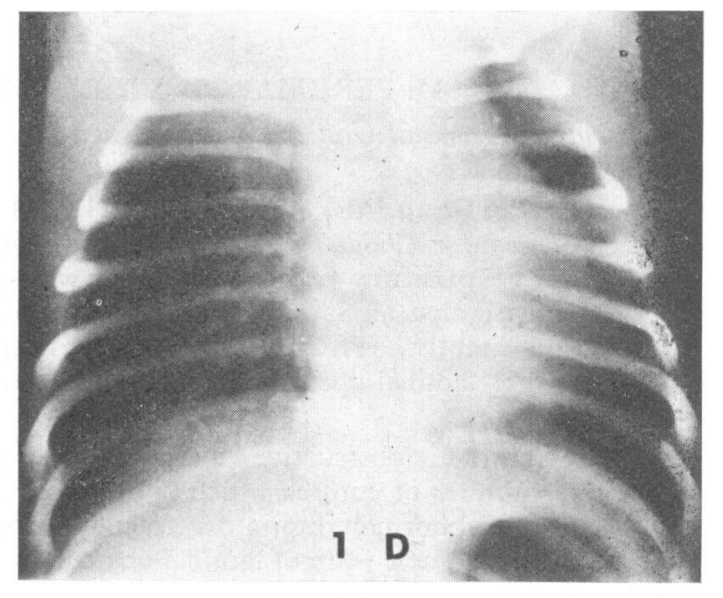

(a)

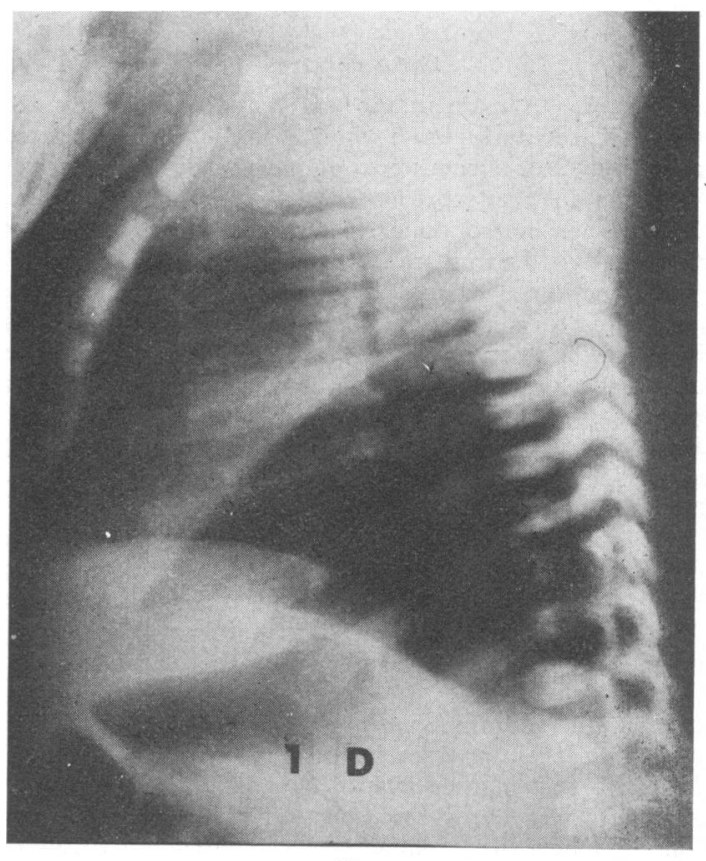

(b)

FIG. 3.-Case 2. (a) Note mild degree of bilateral pulmonary hyperinflation and (b) partial collapse of the left upper lobe. 
cyanosis was severe, the chest was barrel-shaped, the percussion note was tympanitic, and bronchi and râles were heard bilaterally. Gradual clinical improvement occurred with supportive measures, and the infant was discharged home at the age of 3 weeks.

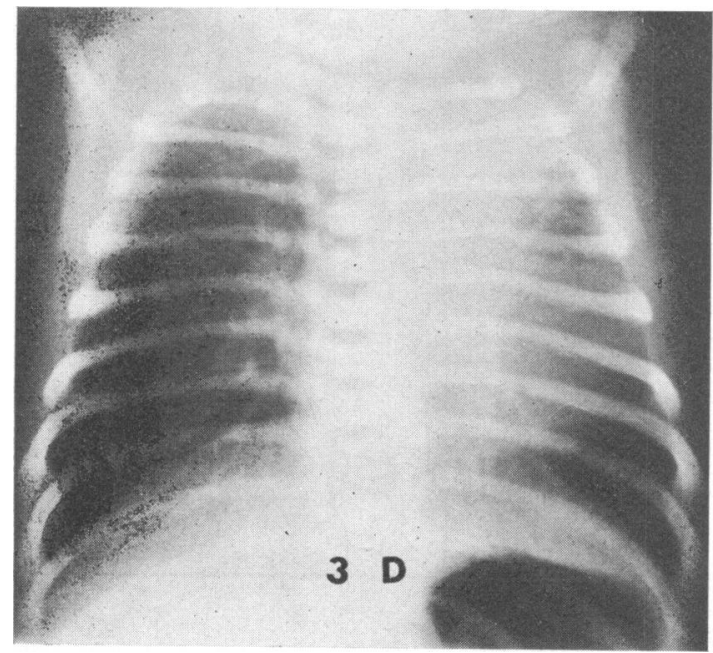

FIG. 4.-Case 2. Aged 3 days; there is complete collapse of the left upper lobe.

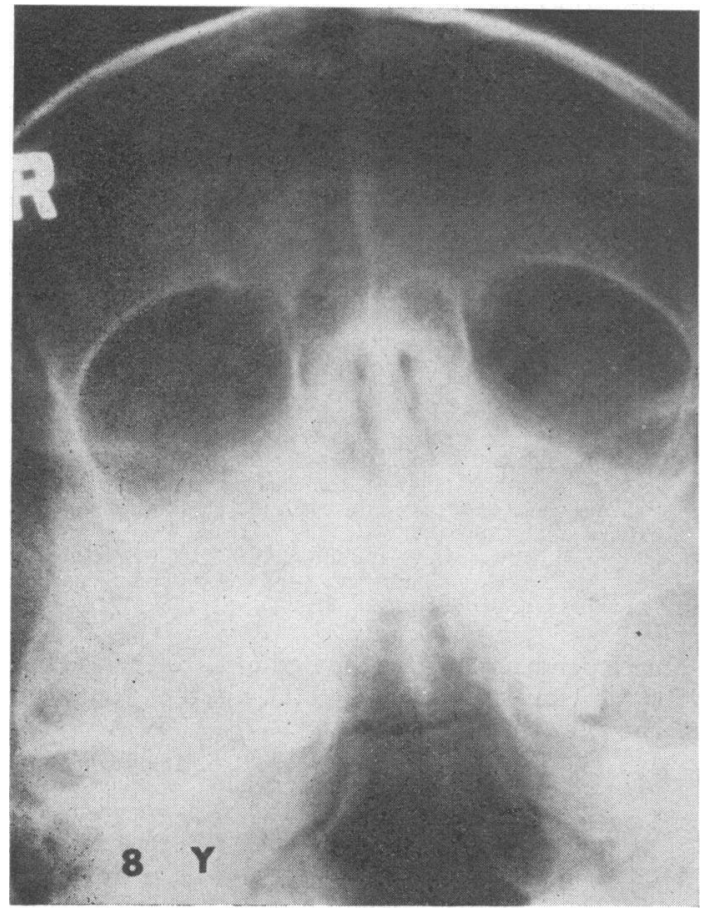

FIG. 5.-Case 2. Note bilateral opacification of maxillary antrum and ethmoid air cells consistent with sinusitis.
During the next 2 years there were 10 hospital admissions totalling 30 weeks for recurrent bronchopneumonia, lobar atelectasis, otitis media, and mastoiditis. On one occasion mastoiditis was complicated by staphylococcal meningitis. Leucocyte counts during episodes of illness showed neutrophilia. Since the age of 2 years she has suffered from several episodes of bronchitis each year and chest $x$-ray at the age of 5 years showed deformity of the bony thorax, pulmonary overaeration, and chronic lung changes involving the right middle lobe and lingula of the left upper lobe, and probably bronchiectatic changes in these lobes.

At the age of 8 years she is an active child, with normal physical and mental development, her weight and height at the 25th centile and head circumference at the 40th centile. The fingers are not clubbed. Chest $x$-ray appeared essentially unchanged and $x$-ray of the paranasal sinuses showed bilateral opacification of the maxillary antra and ethmoid air cells (Fig. 5).

Laboratory investigations are summarized in Table I. Sweat electrolytes were normal. Two attempts to obtain duodenal fluid at the age of 8 years were unsuccessful.

Family history. The parents are healthy firstcousin Yemenite Jews. No family history of pulmonary disease or neonatal illness was obtained. There is one normal brother, and one brother aged 10 years with mild mental retardation and convulsive disorder of unknown cause.

\section{Discussion}

The 2 sibs described presented with a disease pattern attributable to chronic variable obstructive airways disease of both upper and lower respiratory tracts. Lower respiratory tract obstruction was evidenced by recurrent atelectasis of different lobes from birth, frequent wheezing attacks, and clinical and radiological evidence of overinflation of the lungs. Obstructive phenomena of the upper respiratory tract included recurrent otitis media, both purulent and secretory, recurrent mastoiditis, and chronic sinusitis.

Familial conditions associated with chonic obstructive airways disease in childhood include cystic fibrosis, Kartagener's syndrome, allergy, and $\alpha_{1}$-antitrypsin deficiency, the latter being excluded by specific laboratory findings. The early postnatal onset of symptoms is not compatible with an allergic aetiology.

Cystic fibrosis (see Table II) is excluded by the atypical clinical course in both infants and the normal sweat electrolytes (in the absence of oedema which may cause false negative results). di Sant'Agnese (1953) reported lobar atelectasis due to cystic fibrosis in infancy; of 22 cases, the youngest patient mentioned was 3 weeks old. Shwachman, Pryles, and Gross (1956) followed 15 newborns 
TABLE II

Comparison of features of Cases 1 and 2 with those of cystic fibrosis

\begin{tabular}{|c|c|c|}
\hline & Cystic fibrosis & Cases 1 and 2 \\
\hline $\begin{array}{l}\text { Lower respiratory tract } \\
\text { Age of onset of atelectasis } \\
\text { Recurrent atelectases } \\
\text { Wheezing episodes } \\
\text { Emphysema } \\
\text { Bronchiectasis }\end{array}$ & $\begin{array}{l}\text { Weeks or months } \\
+ \\
+ \\
+ \\
+\end{array}$ & $\begin{array}{l}\text { Hours } \\
\quad+ \\
+ \\
+ \\
+\end{array}$ \\
\hline $\begin{array}{l}\text { Upper respiratory tract } \\
\text { Otitis media } \\
\text { Sinusitis }\end{array}$ & $\begin{array}{l} \pm \\
+\end{array}$ & $\begin{array}{l}+ \\
+\end{array}$ \\
\hline $\begin{array}{l}\text { Abnormal mucus } \\
\text { Clinically viscid } \\
\text { Increased respiratory gland activity } \\
\text { Abnormal duodenal fluid }\end{array}$ & $\begin{array}{l}+ \\
+ \\
+\end{array}$ & $\stackrel{+}{?}$ \\
\hline Malabsorption & + & - \\
\hline Biliary tract disease & \pm & - \\
\hline Salivary gland disease & + & $?$ \\
\hline Raised suceat sodium & + & - \\
\hline
\end{tabular}

+ , frequently present; -, absent; ?, not fully investigated.

presenting with meconium ileus; the earliest onset of respiratory symptoms occurred at the age of 2 weeks. Onset of atelectasis in the first hours after birth has not, to our knowledge, been described in cystic fibrosis.

Two female sibs in an English family have recently been described who suffered from fatal chronic suppurative lung disease mimicking cystic fibrosis (Cogswell, Risdon, and Taylor, 1974). Repeated sweat electrolyte estimations were within normal limits, and though histological changes in the salivary glands were identical to those of cystic fibrosis, the pancreas was microscopically normal. The authors considered that the disease might represent a pure pulmonary form of cystic fibrosis. The present cases might be similarly characterized but extrapulmonary manifestations could not be excluded in these living patients. The malady described in this report differed, moreover, from that described by Cogswell et al. (1974) in that the neonatal course was stormy and the subsequent course in childhood was relatively benign.

The widespread obstructive phenomena of upper and lower airways in the subjects of this report may be due to abnormal mucus or ciliary dysfunction. The former at least appears to be implicated owing to the abnormal mucus observed clinically. Because of the unique clinical and radiological course, as well as the normal sweat electrolyte values, we would characterize this disease as familial noncystic fibrosis mucus inspissation of the respiratory tract.

Parental consanguinity, absence of other affected family members, and affliction of both sexes all suggest an autosomal recessive inheritance for the disease in the family described.

\section{REFERENCES}

Cogswell, J. J., Risdon, R. A., and Taylor, B. (1974). Chronic suppurative lung disease in sisters mimicking cystic fibrosis. Archives of Disease in Childhood, 49, 520.

di Sant'Agnese, P. A. (1953). Bronchial obstruction with lobar atelectasis and emphysema in cystic fibrosis of the pancreas. Pediatrics, 12, 178.

Shwachman, H., Pryles, C. V., and Gross, R. E. (1956). Meconium ileus. A clinical study of twenty surviving patients. American fournal of Diseases of Children, 91, 223.

Correspondence to Dr. M. Perlman, Neonatal Unit, Hadassah University Hospital, P.O. Box 499, Jerusalem, Israel. 